\title{
DYNAMIC TRACKING CONTROL AND WORM GEAR GRINDING
}

\author{
Chih-Cheng Peng ${ }^{1}$, Jing-Kai Nian², Shiaw-Wu Chen ${ }^{3}$, Thong-Shing Hwan ${ }^{4}$ \\ ${ }^{1}$ Graduate Institute of Electrical and Communications Engineering, Feng Chia University, 40724, Taiwan, R.O.C \\ ${ }^{2}$ Graduate Institute of Automatic Control Engineering, Feng Chia University, 100, Wenhwa Road, Seatwen \\ Taichung 40724, Taiwan, R.O.C \\ ${ }^{3}$ Graduate Institute of Automatic Control Engineering, Feng Chia University, 100, Wenhwa Road, Seatwen \\ Taichung 40724, Taiwan, R.O.C \\ ${ }^{4}$ Graduate Institute of Automatic Control Engineering, Feng Chia University, 100, Wenhwa Road, Seatwen \\ Taichung 40724, Taiwan, R.O.C
}

\begin{abstract}
Gear grinding process is the last fine process after heat treatment of the gear. At present, the industrial circles mostly use the worm generating gear grinding for mass production of gear grinding process. The worm generating gear grinding machine used by industries in Taiwan was imported from abroad, and the cost of controller is often considered to account for $30 \%$ to $50 \%$ of the machine. In this article, first we establish the theoretical involute worm mathematical formulas and then describe the spatial relationship between worm and gear by coordinate transformation and derive its trajectory equations, finally we get the equations of worm and gear by using engaged theory. For the Electronic Gear Box (EGB) controller design, the key technologies include synchronous tracking between the leading axis and the following axis which must be considered first in the worm grinding mechanism and the simultaneous motion control between the leading axes accommodated to the gear-shape construction. In this research, we use Matlab to accomplish the simulation of involute gear-shape and 3D motion simulation of gear grinding.
\end{abstract}

Keywords: Synchronous Tracking, Simultaneous Motion Control, Electronic Gear Box, Worm Gear Grinding ***

\section{INTRODUCTION}

So far, in Taiwan, the hobbing, grinding or gear testing machines mostly rely on Japan and Europe and other countries. The gear technology of manufacture and design is quite lacking, therefore, how to enhance the gear accuracy and hobbing process capability is the primary key problem for the domestic gear industry.

Gear is a mechanical element of the most commonly used in daily life. And among the mechanical transmission device, from small device as a clock watch to large machine as aircraft and a turbine of ship, we can see the trace of the gear. Therefore, the gear accuracy of design andmanufacturing is increasingly requested to high. But, the controller of processing machine isthe commercial secrets forvarious manufacturers, its technologies have some subtle, so the price of controller is often accounted for most of the machine cost.

Gear grinding process is divided intotwo categories including profile grinding methodand generating grinding method as shown Figure 1.Based on the consideration of efficiency and accuracy, each possesses with its advantages and disadvantages as well as its range of applications, the gear grinding has evolved totwo kinds of developing trends, which are profile wheel grinding and worm wheel grinding.
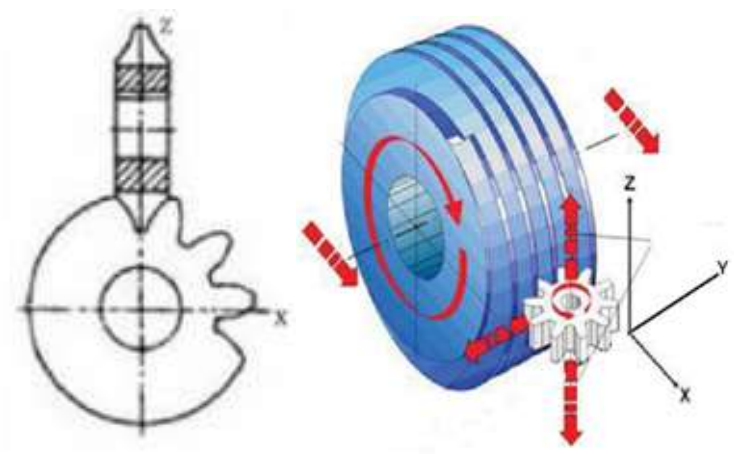

(a) profile grinding

(b) generating worm wheel grinding

Fig 1: Gear grinding method

\section{SYSTEM ARCHITECTURE}

In this research, we consider the RZ-400-type CNC generative worm wheel gear grinding machine as a research model, which relative position of grinding wheel and its work-piece is shown in Fig. 2. There are three translational axes $(\mathrm{X}, \mathrm{Y}, \mathrm{Z})$ and three rotation shafts $(\mathrm{A}, \mathrm{B}$, C). $\mathrm{X}$-axis is the radial feed axis, $\mathrm{Y}$-axis is tangential feed axis, and $\mathrm{Z}$ is the axial feed axis. $\mathrm{A}$ is control installation angle of the tool rotation axis, $\mathrm{B}$ is grinding wheel rotation axis, and $\mathrm{C}$ is processing gear rotation axis. 


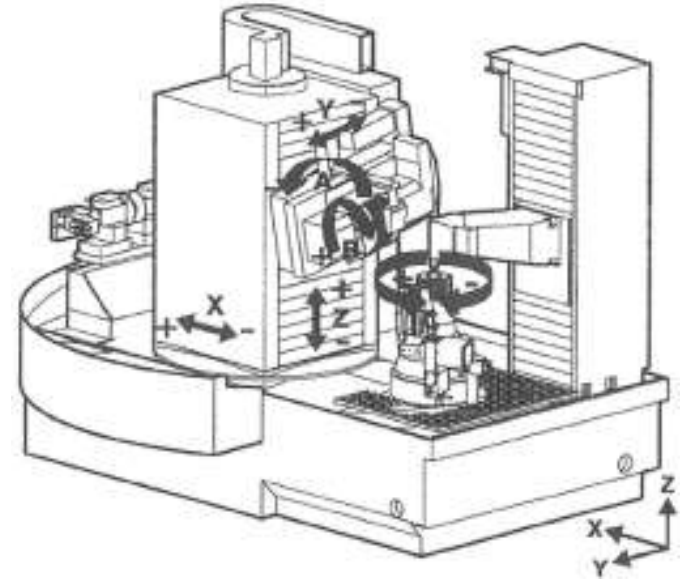

Fig 2: Reishauer RZ-400

The basic principle operation of electronic gear box is to control the feed rate of each feed axis, and the rotation angle of rotation axis and the engagement between the constructed teeth. It is necessary to match all axes with a certain ratio together, and it is driven by a motor that the rotation rate of both axes must be the same, as shown in Fig. 3. In the following equation, it shows that the constructed speed of active axis (worm wheel + wheel tangential feed + wheel axial feed) is equal to the passive axis(gear wheel) speed.

$\omega_{\mathrm{w}} \frac{\mathrm{Z}_{\mathrm{w}}}{\mathrm{Zg}}+\Delta \omega_{\mathrm{gt}}+\Delta \omega_{\mathrm{gz}}=\omega_{\mathrm{g}}$

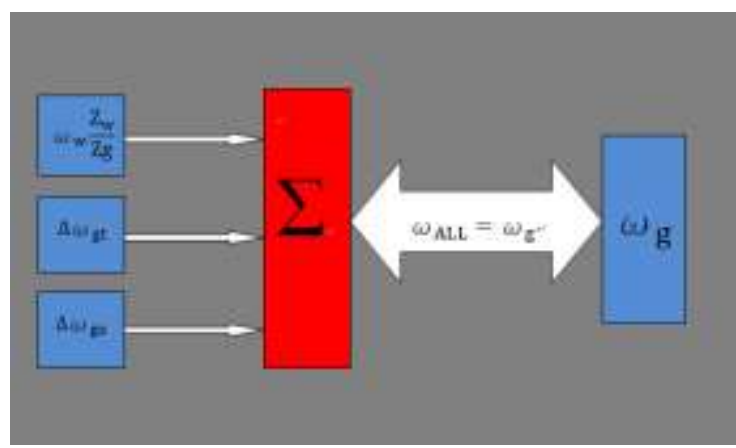

Fig 3: Basic architecture of electronic gear box

\section{CONSTRUCTION OF THE WORM GRINDING}

\section{INVOLUTE}

\subsection{Involute}

Tooth shape of gear is roughly is divided into two categories: cycloid gear tooth and involute gear tooth. And the latter is the most widely used.

Theoretical derivation of general standard involute can be used to define the line of involute that the rope is wound on a cylinder, and pulling the top of rope out slowly. The passing trajectory of rope top is called involute. It is shown in Fig. 4. Assume the base circle center to be the origin, base circle radius is $r$, involute opening changing angle is $t$, and $\mathrm{M}$ is any point of involute.If it is a plane curve then $\mathrm{z}$-axis is equal to $0 . \mathrm{Set} \angle \mathrm{XOB}=\mathrm{t}, \overline{\mathrm{OB}}=\mathrm{r}, \widehat{A B}=\mathrm{S}$. Plot the $\overline{\mathrm{BC}}$,
$\overline{\mathrm{ME}}$ vertical line of $\overline{\mathrm{OX}}$ through $\mathrm{B}, \mathrm{M}$ point respectively and intersect at $\mathrm{C}, \mathrm{E}$ point ; pass throughM point to do the vertical line $\overline{\mathrm{BC}}$ and intersect $\overline{\mathrm{BC}}$ atDpoint.The involute equation is:

$M(X, Y)=\left\{\begin{array}{l}X=r * \cos (t)+S * \sin (t) \\ Y=r * \sin (t)-S * \cos (t)\end{array}\right.$

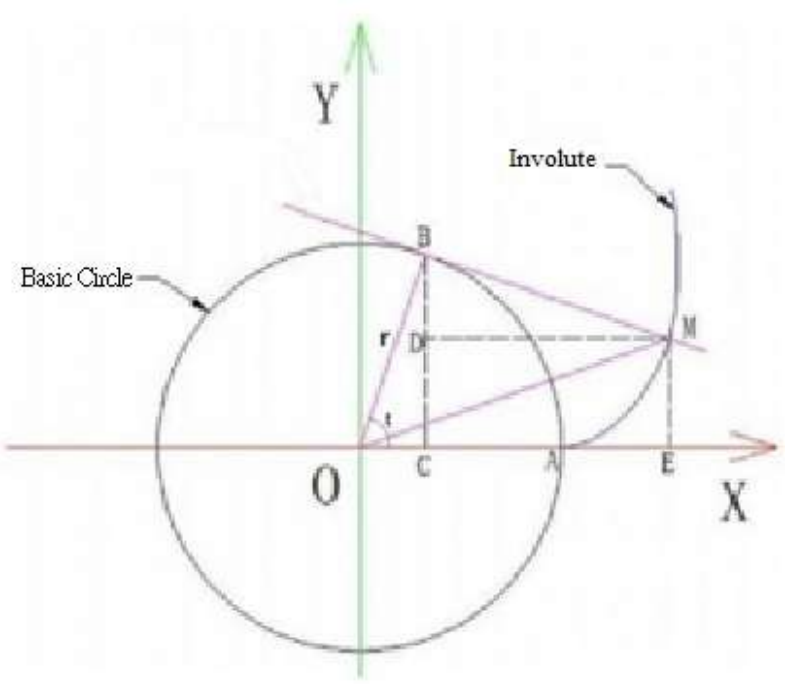

Fig 4: Involute

\subsection{Theoretical Involute Worm Formula}

The formation of the worm tooth surface might be imagined as a segment line is tangent to a spiral line of base cylinder. This segment is a trajectory of spiral motion along the spiral line in three-dimensional space. That is the so called worm tooth surface, as shown in Figure 5. $\lambda_{\mathrm{b}}$ is the lead angle, $\mathrm{r}_{\mathrm{b}}$ is is the base cylinder radius, $\theta$ is the angle of helical motion, $\mathrm{T}$ is working range of tooth surface which is the straight length of the spiral line from point A to B. Fig.5(a)is the right flank of worm, and Fig.5(b) is the left flank. Therefore, we can get the involute worm tooth surface equation as follows :

$$
\begin{gathered}
W=\left[\begin{array}{llll}
x & y & z & 1
\end{array}\right]^{\mathrm{T}} \\
\mathrm{x}=\mathrm{r}_{\mathrm{b}} \cos \theta \mp \mathrm{T} \cos \lambda_{\mathrm{b}} \sin \theta \\
\mathrm{y}=\mathrm{P} \theta \pm \mathrm{T} \sin \lambda_{\mathrm{b}} \\
\mathrm{z}=\mathrm{r}_{\mathrm{b}} \sin \theta \pm \mathrm{T} \cos \lambda_{\mathrm{b}} \cos \theta
\end{gathered}
$$

Where, Pis spiral constant, $\mathrm{P}=\mathrm{r}_{\mathrm{b}} \tan \lambda_{\mathrm{b}}$, and the required working range of worm tooth surface is between the outer diameter and root diameter, so the range of $\mathrm{T}$ :

$\left(\frac{\sqrt{r_{f}^{2}-r_{b}^{2}}}{\cos \lambda_{b}}\right) \leqq T \leqq\left(\frac{\sqrt{r_{a}^{2}-r_{b}^{2}}}{\cos \lambda_{b}}\right)$ 

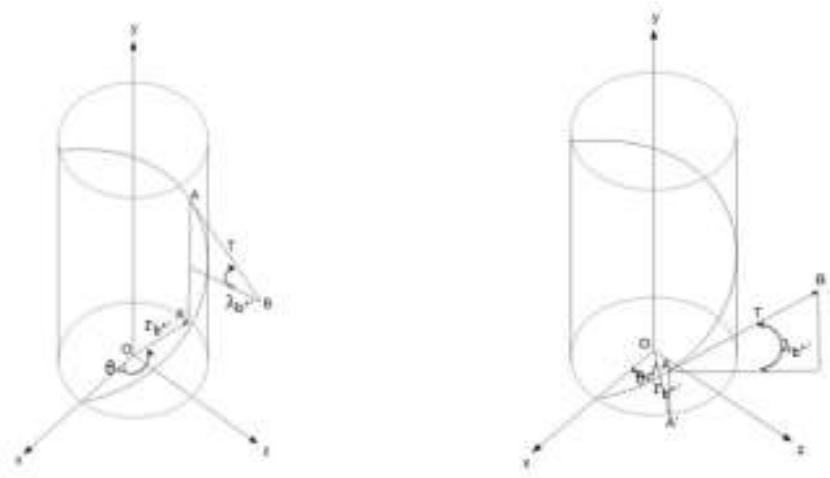

(a) theleft flank (b)the right flank

Fig 5: Dextral involute worm tooth surface schematic

\subsection{Coordinate Transformation}

The establishment of a worm gear coordinate system is shown in Figure 6.Coordinate of worm is $Q_{w}, Q_{1}$ is the coordinate of $\mathrm{Q}_{\mathrm{w}}$ rotates $\psi_{\mathrm{w}}$ angle around $\mathrm{y}_{\mathrm{w}}$ axis, Then along $\mathrm{y}_{\mathrm{w}}$ axis to move $\mathrm{E}_{\mathrm{t}} ; \mathrm{Q}_{2}$ coordinate is obtained by rotating rotation $\mathrm{E}_{\gamma}$ around $\mathrm{x}_{1}$ axis $; \mathrm{Q}_{3}$ is the coordinate $\mathrm{Q}_{2}$ along $\mathrm{x}_{2}$ axis to move $\mathrm{E}_{\mathrm{r}}$; And then move up $\mathrm{E}_{\mathrm{z}}$. The coordinate of gear is $\mathrm{Q}_{\mathrm{g}}$. Rotating $\psi_{\mathrm{g}}$ angle, $\mathrm{x}_{\mathrm{g}}, \mathrm{y}_{\mathrm{g}}$ axes of $\mathrm{Q}_{\mathrm{g}}$ can fit $\mathrm{x}_{3}, \mathrm{y}_{3}$ of $\mathrm{Q}_{3} \cdot \psi_{\mathrm{w}}$ is the rotational angle of worm, $E_{t}$ is the amount of movement in the tangential direction, $\mathrm{E}_{\gamma}$ is the install angle of worm, $\mathrm{E}_{\mathrm{r}}$ is the radial feed amount of worm, $\mathrm{E}_{\mathrm{z}}$ is the axial feed amount of worm, $\psi_{\mathrm{g}}$ is the rotation angle of gear.

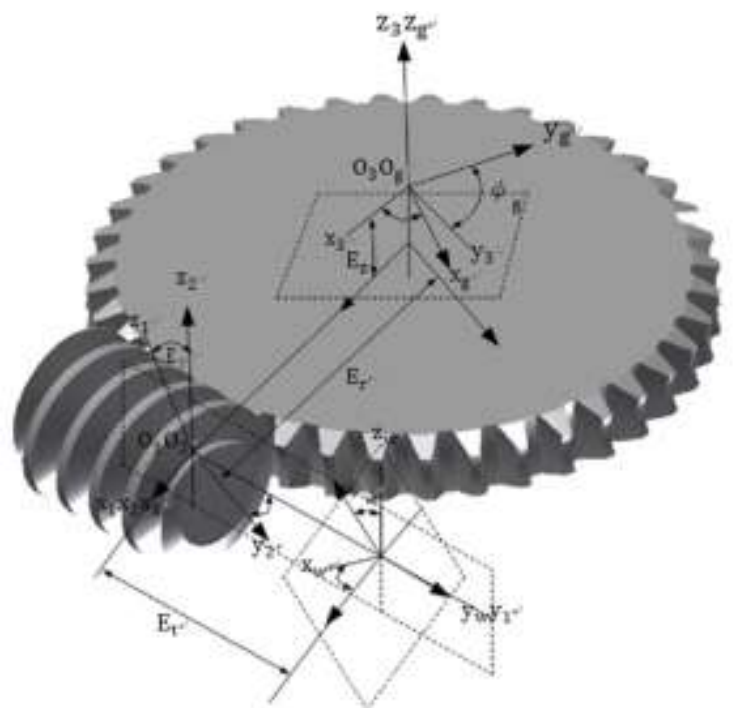

Fig 6: Coordinate conversion system of the worm and gear

Therefore, we can deduce the transfer matrix for each coordinate system :

$M_{g w}=M_{g 3} M_{32} M_{21} M_{1 w}=\left[\begin{array}{cccc}a_{11} & a_{12} & a_{13} & a_{14} \\ a_{21} & a_{22} & a_{23} & a_{24} \\ a_{31} & a_{32} & a_{33} & a_{34} \\ 0 & 0 & 0 & 1\end{array}\right]$
The worm mathematical equation of theoretical involute can be obtained as the following trajectory equation through the coordinate transformation of equation (5)

$r_{w}=M_{g w} r=\left[x_{w} y_{w} z_{w} 1\right]^{T}$

\subsection{Meshing Theory}

During the cutting or grinding teeth, the relation between the tool and the gear or a worm and the gear must mutual engaging together which certainly satisfy the engagement theorem and then generate the same contour line.

Suppose a pair of gears that can be smoothly transmitted the power we want, it is said that the gears mesh with each other, the tooth profile will be conjugated curve or conjugated surface. From this, if a gear tooth is known, and the relationship between the movements of the two gears is also known in space, then another gear tooth shape can be derived theoretically by the engagement of the meshed gear tooth.

There are two surfaces, $K_{1}$ and $K_{2}$, meshing in the space. And the instantaneous common tangent $\mathrm{S}$ has a point $\mathrm{M}$ of the two surfaces, and point $\mathrm{M}$ is also the instantaneous contact point of these two surfaces. Both have a common normal vector $\mathrm{N}$ on the point $\mathrm{M}$, and the relative velocity $\mathrm{V}$ of $\mathrm{K}_{1}$ and $\mathrm{K}_{2} 2$ at point $\mathrm{M}$. When the meshing movement of two engagement surfaces happens, there is no relative speed in the direction of $\mathrm{N}$. Therefore, $\mathrm{V}$ must be on the common tangent surface $\mathrm{K}$ which is perpendicular to $\mathrm{N}$.

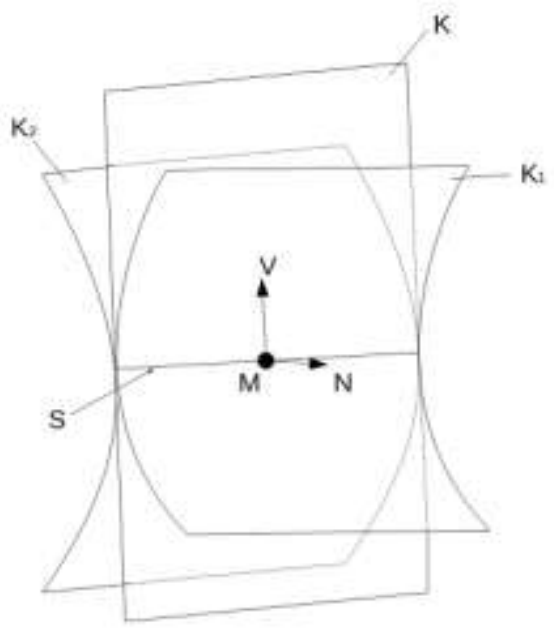

Fig 7: Meshing theory

From this, $\mathrm{V}$ and $\mathrm{N}$ are perpendicular to each other, so the inner product of two vectors must be zero, and then the meshing equation is :

$\mathrm{N}^{\cdot} \mathrm{V}=0$ 
Worm normal vector $\mathrm{N}$ can be obtained by differentiating partially the worm mathematical equation with respect to variables $\mathrm{T}$ and $\theta$ and do the inner product. Therefore,

$N=\frac{\partial_{T} r(T, \theta) \times \partial_{\theta} r(T, \theta)}{\left|\partial_{T} r(T, \theta) \times \partial_{\theta} r(T, \theta)\right|}=\frac{[N x N y \quad N z}{\sqrt{N^{2}+N^{2}+N^{2}}}$

$$
\begin{array}{r}
\mathrm{N}_{\mathrm{x}}=\sin \lambda_{\mathrm{b}} \sin \theta \\
\mathrm{N}_{\mathrm{y}}=\cos \lambda_{\mathrm{b}} \\
\mathrm{N}_{\mathrm{z}}=-\sin \lambda_{\mathrm{b}} \cos \theta \\
\mathrm{N}_{\mathrm{g}}=\mathrm{R}_{\mathrm{gw}} \mathrm{N}=\left[\begin{array}{lll}
\mathrm{Nx}_{\mathrm{w}} & \mathrm{Ny}_{\mathrm{w}} & \mathrm{Nz}_{\mathrm{w}}
\end{array}\right]
\end{array}
$$

In the movement of worm and gear meshing, the worm corner $\psi_{\mathrm{w}}$ is the motion parameters, soV $\mathrm{g}$ worm tracks by partial differential equations is obtained for $\psi_{\mathrm{w}}$ :

$V_{g}=\frac{\partial r_{w}}{\partial \psi_{w}}=\left[\begin{array}{lll}V_{x} & V_{y} & V_{w}\end{array}\right]^{T}$

Substituting the formula (9) and formula (10) to formula(7) can obtain the worm gear engaging equation:

$$
\begin{array}{r}
\mathrm{N}_{\mathrm{g}} \cdot \mathrm{V}_{\mathrm{g}}=0 \\
\Rightarrow \mathrm{Ng}_{\mathrm{x}} \mathrm{Vg}_{\mathrm{x}}+\mathrm{Ng}_{\mathrm{y}} \mathrm{Vg}_{\mathrm{y}}+\mathrm{Ng}_{\mathrm{z}} \mathrm{Vg}_{\mathrm{z}}=0
\end{array}
$$

\section{GRINDING CONTROL OF WORM GRINDING}

\subsection{The Corner Compensation of Grinding Teeth}

When the worm and gear are joggled, there exists a relational formula of rotation speed ratio for the rotation angle, it means that the ratio of the revolution number equals to the inverse of the gear ratio. If it is processing helical gears, we should consider the relationship between the feed amount and rotation speed additionally. There are three kinds of feed amount in grinding process, $W_{t}$ tangential feed, $W_{r}$ radial feed, and $W_{z}$ axial feed.Because the radial feed axis ( $\mathrm{X}$-axis) is perpendicular to the gear rotation axis (C-axis), the feed amount is nothing to do with gear rotation angle, so it is no need to consider the speed compensation. In the following, $G_{x}, G_{y}, G_{z}$ is the coordinate of gear.

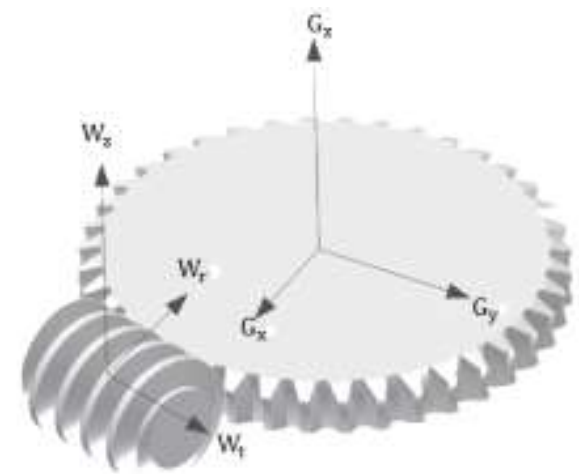

Fig 8: The feed axis of worm and gear coordinate axis

\subsubsection{Axial feed}

The worm in the direction $\mathrm{W}_{\mathrm{z}}$ move the shaft of grinding gears up or down, that is axial feed. Its function of this axis is the processing of the grinding gear in the shaft tooth width direction. When the larger the amount of a single feed, the shorter the time required to complete the polishing. But it also derives a larger burrthat can inducea cutting trace of unsmoothing and larger error. Therefore, a single feed amount size and accuracy trade-offs must be carefully assessed to achieve optimum efficiency.

Theoretically, worm gear should be fed in the direction of the helix (helicalline of straight gear is a straight line), so that it can maintain the speed of the worm and gear ratio relationship. But if it is processed for the helical gear, there is a helix angle $\alpha_{\mathrm{gp}}$, so it must be added to compensate corner, like figure $9, \mathrm{w}_{\mathrm{z}}$ is axial feed amount, $\alpha_{\mathrm{gp}}$ is gear helix angle at the pitch circle, $r_{\mathrm{gp}}$ is gear pitch circle radius, so we can get the derived compensation angle $\Delta \psi_{\mathrm{gz}}$ of axial feed :

$$
\Delta \psi_{\mathrm{gz}}=\frac{\mathrm{w}_{\mathrm{z}} \times \tan \alpha_{\mathrm{gp}}}{\mathrm{r}_{\mathrm{gp}}} \times \frac{180}{\pi}
$$

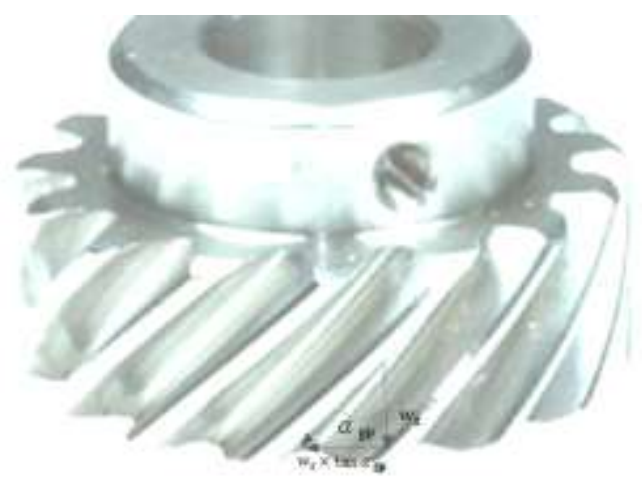

Fig 9.The compensation angle of axial feed

\subsubsection{The Tangential Moving}

If the worm did not move tangentially, it would be only a single wheel grinding face gear, which would cause the debris falling abrasive grinding and accumulate on a single surface, and it would affect the accuracy of machining seriously. Also, it would induce the problems of the implementation difficulty and longtime repair and maintain of grinding wheel, we add chopped worm movement on all surfaces. By doing so, we can have a serious impact when the loss to the grinding teeth, and then grinding wheel dressing, which will greatly improve the accuracy of and efficiency.

When using the worm wheel to grind teeth, the formed worm helical proceeding by worm rotating is considered to simulate the translational behavior of gear processing by using rack knife. So the tangential feed is seen as giving an extra shift amount for rack knife. In Fig. 10, $\mathrm{z}_{\mathrm{w}}$ isthe number of worm teeth mouth, $z_{g}$ is the teeth number of gear, $\mathrm{w}_{\mathrm{t}}$ is the tangent translation amount, andr $\mathrm{gp}_{\mathrm{p}}$ isgear pitch circle radius. Additionally, the worm must consider the induced gear equivalent compensation corner $\Delta \psi_{\mathrm{gt}}$ for tangential movement : 
$\Delta \psi_{\mathrm{gt}}=\frac{\mathrm{z}_{\mathrm{W}}}{\mathrm{z}_{\mathrm{g}}} \times \frac{\mathrm{w}_{\mathrm{t}}}{\mathrm{r}_{\mathrm{gp}}} \times \frac{180}{\pi}$

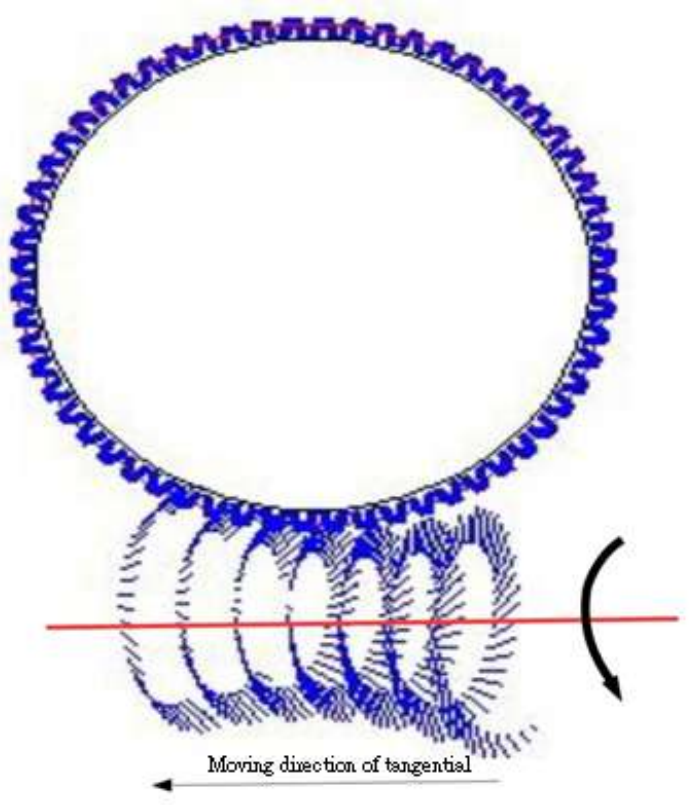

Fig 10: Worm moving of tangential schematic diagram

\subsubsection{Radial Feed}

The worm moves along $\mathrm{W}_{\mathrm{r}}$ to the center axis of the gears, called radial feed.Radial feed is to make worm to move from the tooth roof of gear to the tooth root, and the tuning of the radial amount can also be used to repair various types of gears, asFig.11.1 to 11.3. Where $\mathrm{m}_{\mathrm{n}}$ isvertical modulus, $\alpha_{\mathrm{gp}}$ is helix angle at the pitch circle of the gear, and $\beta_{\mathrm{gn}}$ is vertical pressure angle. Base on the gear wheel theorem, dressing amount $\mathrm{s}$ can be obtained and the relation between $\mathrm{s}$ and the radial feed amount $\mathrm{w}_{\mathrm{r}}$ can be derived as follows :

$$
\mathrm{w}_{\mathrm{r}}=\frac{\mathrm{m}_{\mathrm{n}} \mathrm{s}}{\tan \beta_{\mathrm{gn}}} \cos \alpha_{\mathrm{gp}}
$$

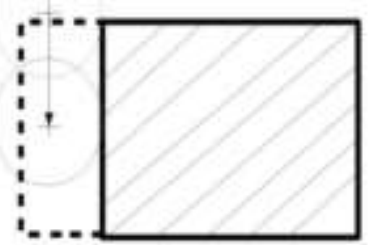

Fig 11.1 Cylindrical

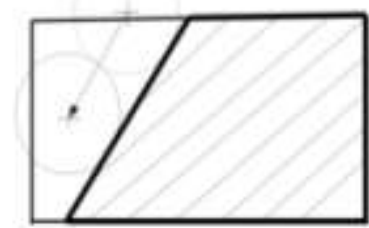

Fig 11.2 Umbrella

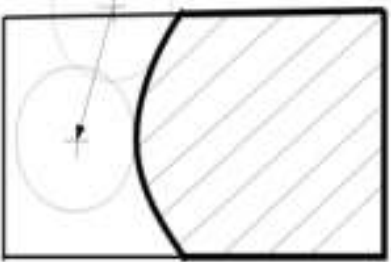

Fig 11.3 Coronal

\subsection{Electronic Gear Box}

In the past, the old-fashioned cutting or grinding machine had some shortcomings, such as complex structure, big operating noise, installation or maintenance and adjustment difficulties, transmission errors and other shortcomings. The electronic gear box(EGB) can achieve the goal of constant velocity ratio, which means to get the synchronized dynamic motion between tool axis and gear wheel axis. For the EGB, we use power electronics and the digital technology to control the tool axis and the work-piece axis. And add the characteristic curve to change the motion relation between the leading axis and the following axis, and adjust the processing path to change the tooth shape or the tooth surface finishing.

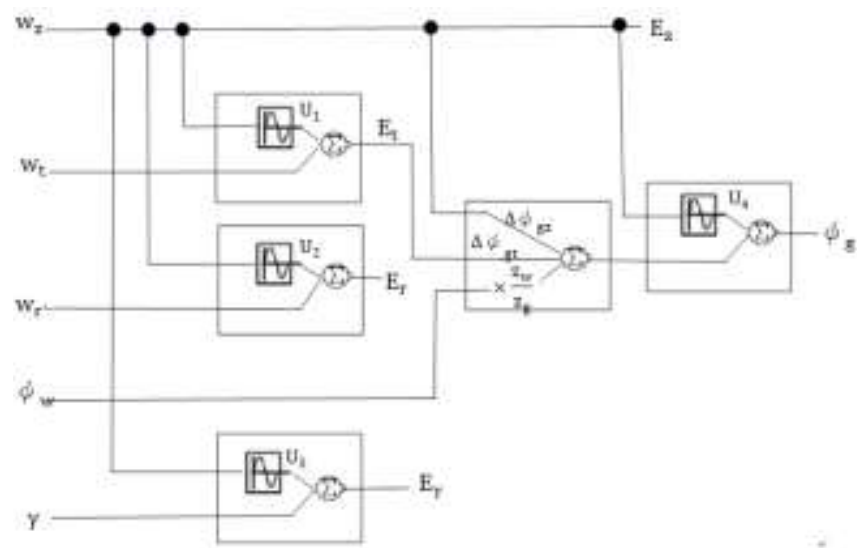

Fig 12: EGBand additional characteristic curve

After adding characteristic curve $\left(\mathrm{U}_{1}, \mathrm{U}_{2}, \mathrm{U}_{3}, \mathrm{U}_{4}\right)$ in each axis, redefine the parameters as follows:

$$
\begin{aligned}
& \mathrm{E}_{\mathrm{t}}=\mathrm{w}_{\mathrm{t}}+\mathrm{U}_{1} \\
& \mathrm{E}_{\mathrm{r}}=\mathrm{w}_{\mathrm{r}}+\mathrm{U}_{2} \\
& \mathrm{E}_{\gamma}=\gamma+\mathrm{U}_{3} \\
& \psi_{\mathrm{g}}=\frac{\mathrm{z}_{\mathrm{w}}}{\mathrm{z}_{\mathrm{g}}} \psi_{\mathrm{w}}+\Delta \psi_{\mathrm{gz}}+\Delta \psi_{\mathrm{gt}}+\mathrm{U}_{4}
\end{aligned}
$$

\subsection{Synchronous tracking}

By electronic gear hobbing, we can know that the shaft rotation speed of the following axis is determined by the leading axis. Following axis speed is $\omega_{\mathrm{g}}$, and leading axes speed is $\omega_{\mathrm{ALL}}$. The speed of the following axis is produced by (1) :

$\omega_{\mathrm{ALL}}=\omega_{\mathrm{w}} \frac{\mathrm{Z}_{\mathrm{w}}}{\mathrm{Zg}}+\Delta \omega_{\mathrm{gt}}+\Delta \omega_{\mathrm{gz}}=\omega_{\mathrm{g}}$

It is the alleged master-slave system. So, if we want to achieve synchronous dynamic hardware in the loop tracking, we can use synchronized master command control system to design as Fig. 13. 


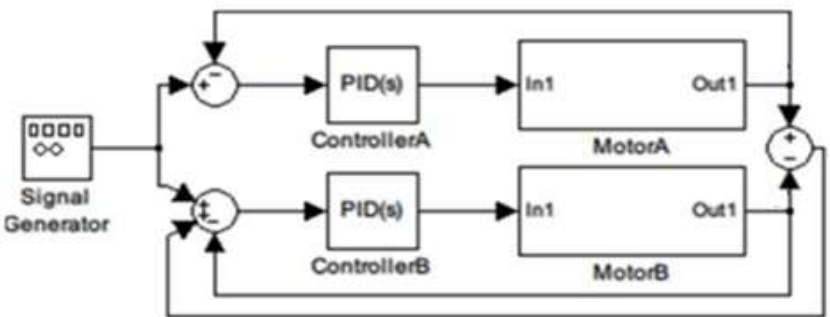

Fig 13.Synchronized master command control system

But there are still some gaps between their system responses, it cannot really be dynamically synchronized tracking. So we add a Fuzzy Controller to correct $\mathrm{K}_{\mathrm{P}}, \mathrm{K}_{\mathrm{I}}, \mathrm{K}_{\mathrm{D}}$ of Motor $\mathrm{B}$ immediately. With this easy-to-use adaptive algorithm can increase the system adaptation, robustness, fault tolerance and reaction speed to compensate for the lack of controlled model, shown as in Fig.14.Motor A is leading axis, Motor B is following axis, e1 is the error of Motor A and Motor B, ec 1 is the change rate of $\mathrm{e} 1$, and $\mathrm{e} 2$ is the error of Motor $\mathrm{B}$.

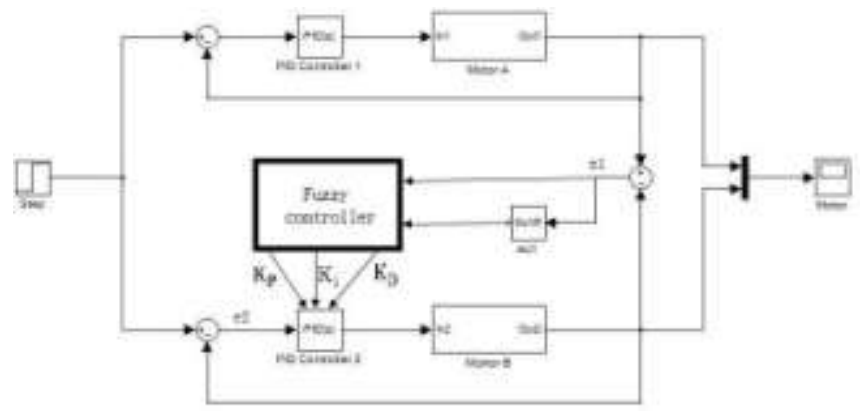

Fig 14: Self-tuning fuzzy-control synchronous tracking

\subsection{Simultaneous Motion Control}

Consider an slash tracking of $\mathrm{X}-\mathrm{Y}$ plane, as shown in Fig. 15, $\theta$ is the angle between the slash and $X$-axis, $P_{d n}, P_{n}$, $\mathrm{P}_{\mathrm{an}}, e_{\mathrm{n}}$ and $\varepsilon_{\mathrm{n}}$ are the command position of point $\mathrm{n}$ in program, servo lagging position, actual position, error of tracking and error of contour. By the geometric relationship, we can get the error of contoure :

$$
\varepsilon=\mathrm{e}_{\mathrm{x}} \sin \theta-\mathrm{e}_{\mathrm{y}} \cos \theta(20)
$$

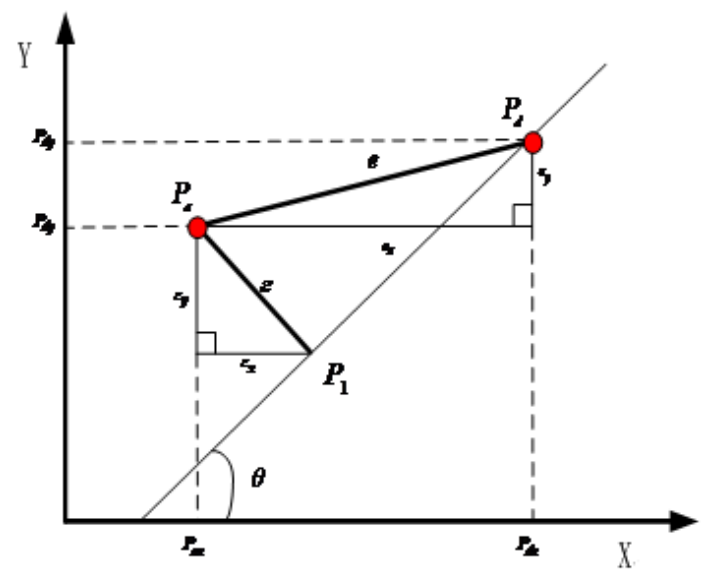

Fig 15: Geometric diagrams of slash contour error
However, during the grinding process, it is necessary to move the radial feed axis (X-axis) and rotate the worm rotation axis (B-axis). Therefore, we can refer the above slash tracking of the X-Y plane. Changing the displacement axis to rotation axis (angle $\psi$ ) and then proceed to execute $\mathrm{X}-\psi$ tracking.The derivation is the same as the slash tracking.

\section{SIMULATION OF WORM GRINDING}

\subsection{Simulation of Involute Teeth Contourin}

\section{MATLAB}

When the worm grinder is grinding, we can simulate the action of the rack knife during gear processing by the rotation of the worm screw forward motion. Therefore, when the rack knife of the involute moves a small distance each time, it will cut the corresponding blade contour of the rack in the blank. Finally the envelope is formed by a set of contour lines, that is the contour of involutegear. Fig.16 is to use MATLAB to simulate the contour of planar gear involute, modulus of gear is 3 , the teeth number of gear is 30 , and the pressure angle is $20^{\circ}$, Fig. 17 is a partially enlarged view.

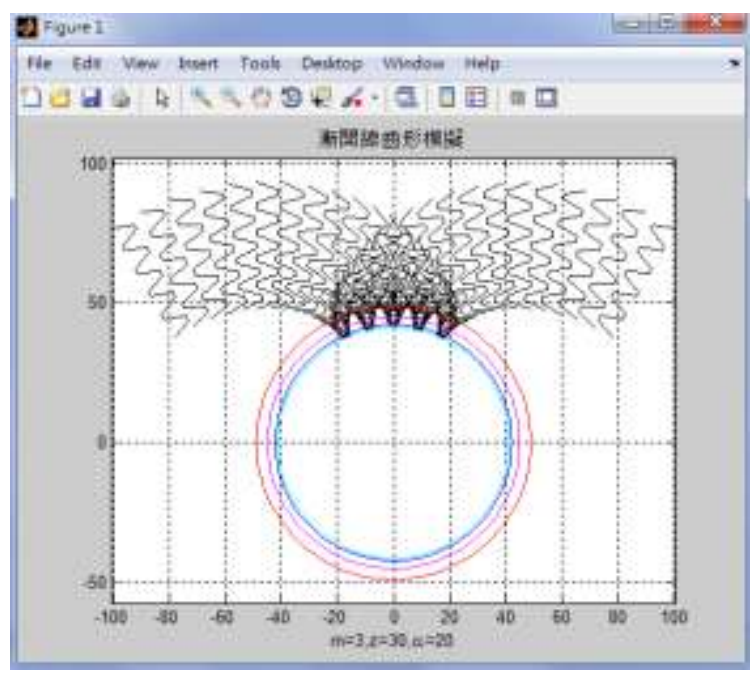

Fig 16: The contour envelope of involute gear

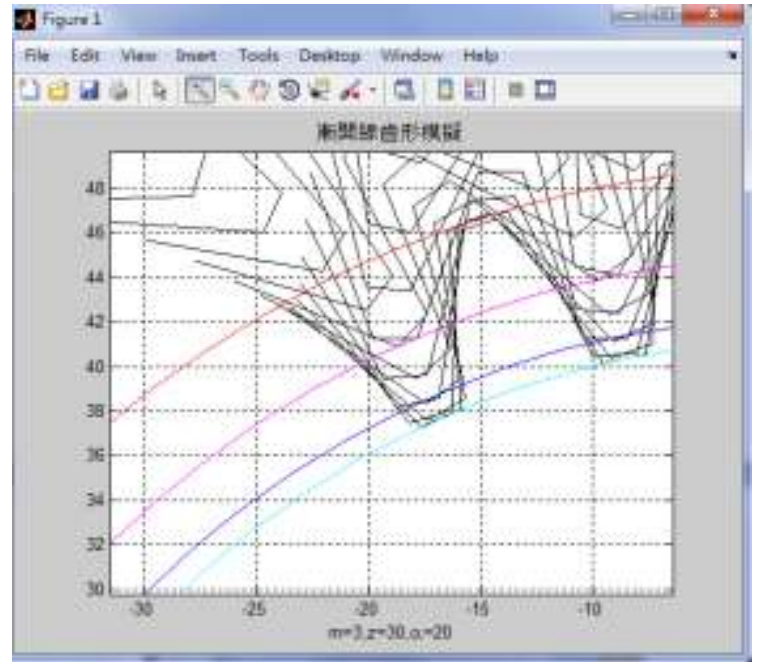

Fig 17: Partial enlarge view 


\subsection{Model of gear and worm}

To construct a plane and 3D models of gear and worm by the parameters of table 5.1 and table 5.2.

Table 5.1 parameters of gear

\begin{tabular}{|l|l|}
\hline Module & 3 \\
\hline Number of Teeth & 60 \\
\hline Pressure Angle & $20^{\circ}$ \\
\hline
\end{tabular}

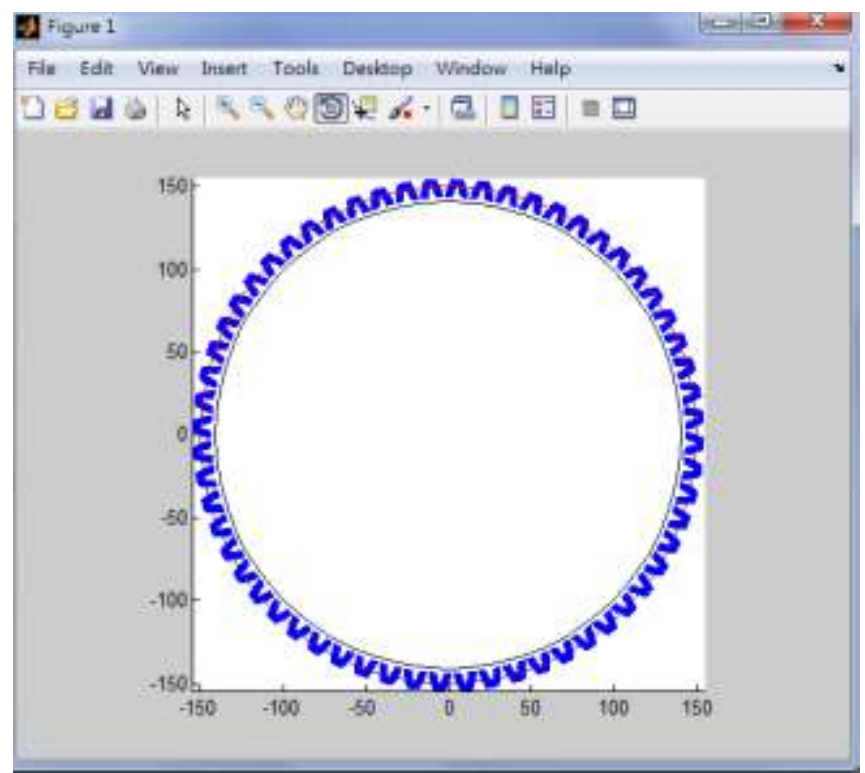

Fig 18: Plane of gears

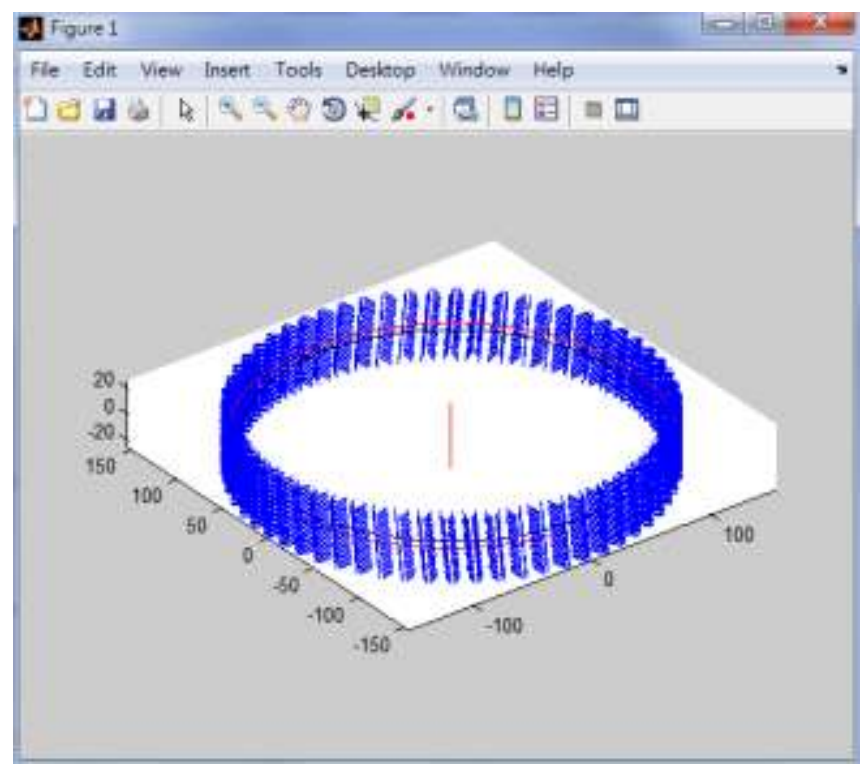

Fig 19: 3-D of gears

Table 5.2 parameters of worm

\begin{tabular}{|l|l|}
\hline Module & 3 \\
\hline Thread & 1 \\
\hline Lead angle & \\
\hline
\end{tabular}

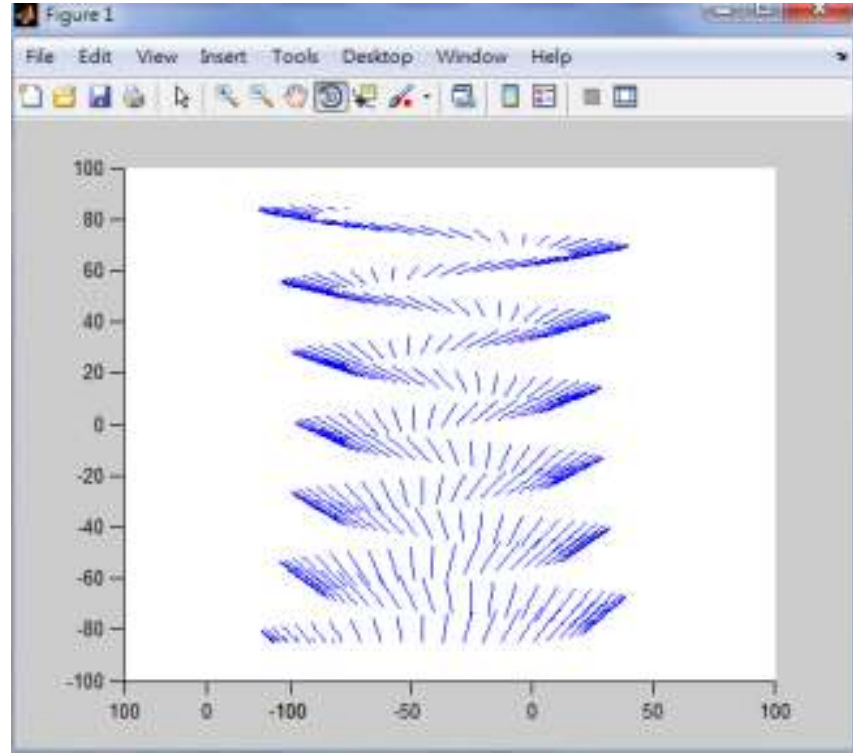

Fig 20: 3-D of worm

\subsection{Involute Trajectory of Worm and Gear}

In Fig. 21, green line is the trajectory of worm, blue line is trajectory of gear.

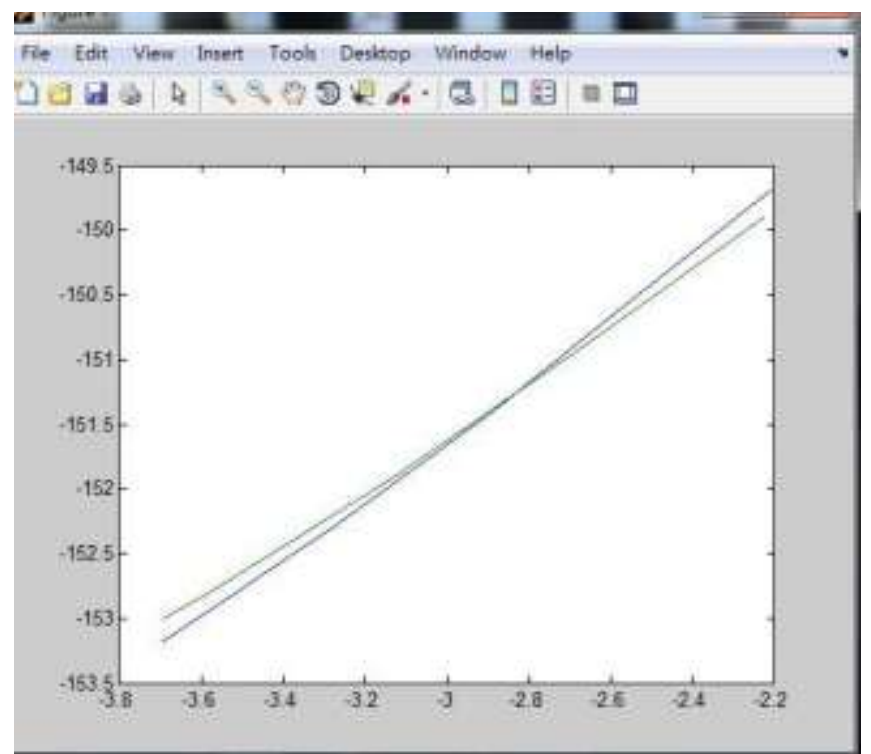

Fig 21: Involute trajectories of worm and gear

\subsection{Simulink Synchronous Tracking Simulation}

Even same motor would have some difference due to the errors of the production process or assembly, or usage of different degree causes to the recession extent. So, in this paper, we create two motors that are similar but not identical. Fig. 22 did not add fuzzy controller, while Fig. 23 is the response of motor. The yellow line is motor $\mathrm{A}$, and the purple line is motor B. 


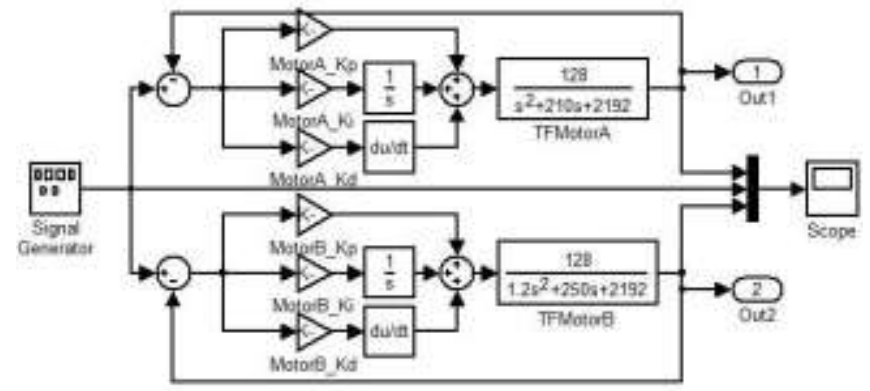

Fig 22 No fuzzy controller

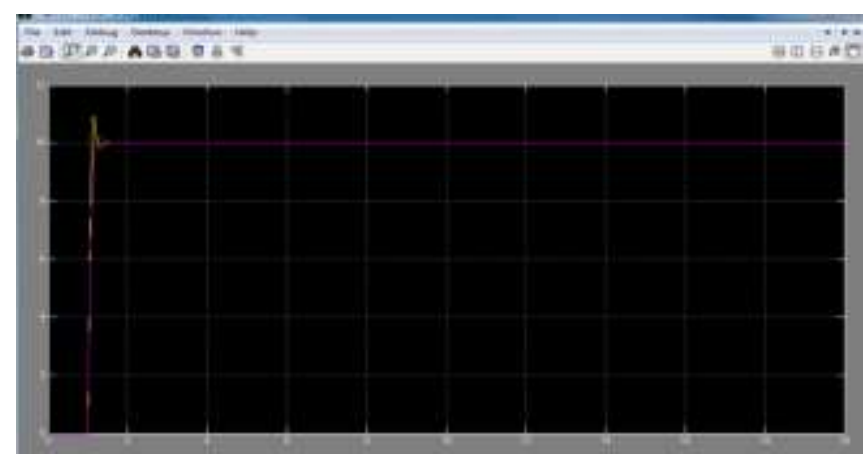

Fig 23 Dynamic tracking without fuzzy controller

In order to make the motor of following axis can quickly keep up with the leading axismotor, we add fuzzy control to accelerate the convergence speed. By using fuzzy theory, we can gather expert knowledge or experience to construct the fuzzy rules, and the data input were classified. And then, produce the corresponding fuzzy outputs which refer to the fuzzy rule. Finally, output the fuzzy classification data by using defuzzification technology.

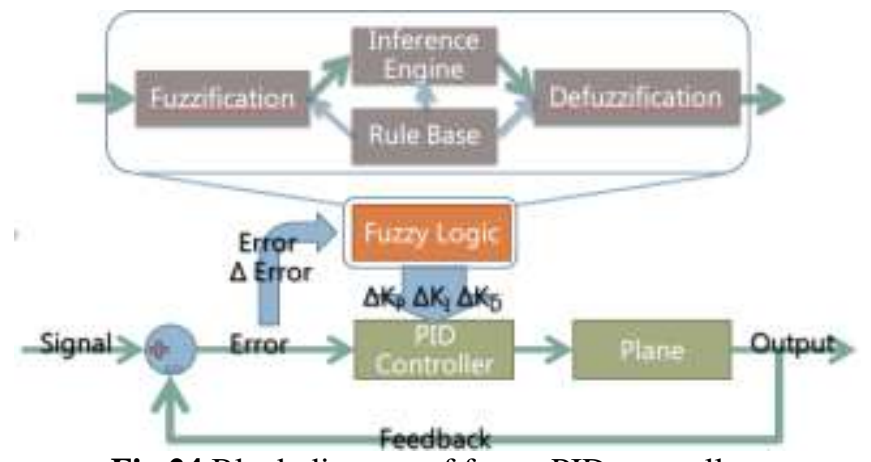

Fig 24 Block diagram of fuzzy-PID controller

In this fuzzy system, I divide the input error into seven Gaussian bands: respectively, a negative large, negative middle, negative small, zero, positive small, positive middle, positive large, and triangle wave linear output. And the rule table is followed PID tuning method and numerous tests to obtain.

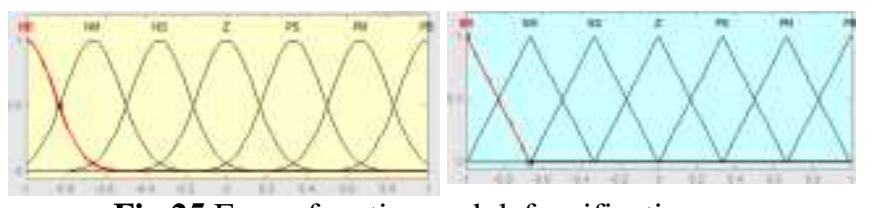

Fig 25 Fuzzy function and defuzzification

Table 5.3 Fuzzy rule of PID

fuzzy rule (kp)
\begin{tabular}{|l|l|l|l|l|l|l|l|}
\hline Error & \multicolumn{7}{|c|}{ Derivative Error } \\
\cline { 2 - 8 } & NB & NM & NS & ZO & PS & PM & PB \\
\hline NB & PB & PB & PM & PM & PS & ZO & ZO \\
\hline NM & PB & PB & PM & PS & PS & ZO & NS \\
\hline NS & PM & PM & PM & PS & ZO & NS & NS \\
\hline ZO & PM & PM & PS & ZO & NS & NM & NM \\
\hline PS & PS & PS & ZO & NS & NS & NM & NM \\
\hline PM & PS & ZO & NS & NM & NM & NM & NB \\
\hline PB & ZO & ZO & NM & NM & NM & NB & NB \\
\hline
\end{tabular}
fuzzy rule (ki)

\begin{tabular}{|l|l|l|l|l|l|l|l|}
\hline \multirow{2}{*}{ Error } & \multicolumn{7}{|c|}{ Derivative Error } \\
\cline { 2 - 8 } & NB & NM & NS & ZO & PS & PM & PB \\
\hline NB & NB & NB & NM & NM & NS & ZO & ZO \\
\hline NM & NB & NB & NM & NS & NS & ZO & ZO \\
\hline NS & NB & NM & NS & NS & ZO & PS & PS \\
\hline ZO & NM & NM & NS & ZO & PS & PM & PM \\
\hline PS & NM & NS & ZO & PS & PS & PM & PB \\
\hline PM & ZO & ZO & PS & PS & PM & PB & PB \\
\hline PB & ZO & ZO & PS & PM & PM & PB & PB \\
\hline
\end{tabular}

fuzzy rule (kd)
\begin{tabular}{|l|l|l|l|l|l|l|l|}
\hline Error & \multicolumn{7}{|c|}{ Derivative Error } \\
\cline { 2 - 8 } & NB & NM & NS & ZO & PS & PM & PB \\
\hline NB & PS & NS & NB & NB & NB & NM & NS \\
\hline NM & PS & NS & NB & NM & NM & NS & ZO \\
\hline NS & ZO & NS & NM & NM & NS & NS & ZO \\
\hline ZO & ZO & NS & NM & NM & NS & NS & ZO \\
\hline PS & ZO & ZO & ZO & ZO & ZO & ZO & ZO \\
\hline PM & PB & PS & PS & PS & PS & PS & PB \\
\hline PB & PB & PM & PM & PM & PS & PS & PB \\
\hline
\end{tabular}

Use fuzzy-PID controller to replace the PID controller of motor B
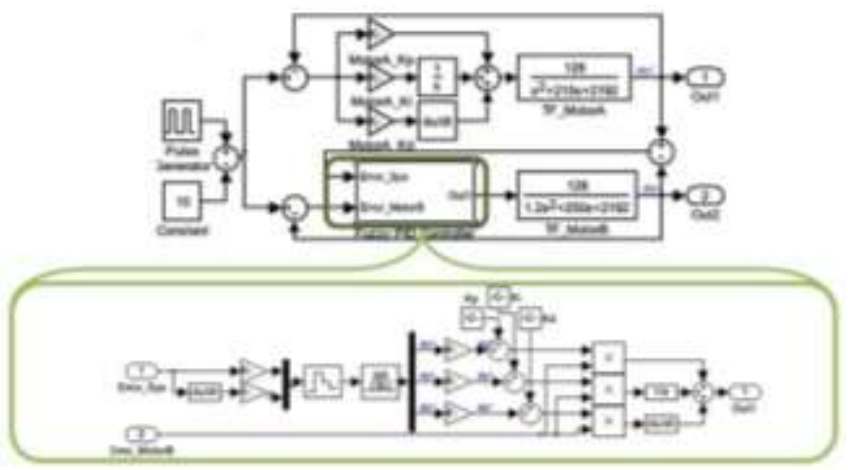

Fig 26 Block diagram of adaptive fuzzy control

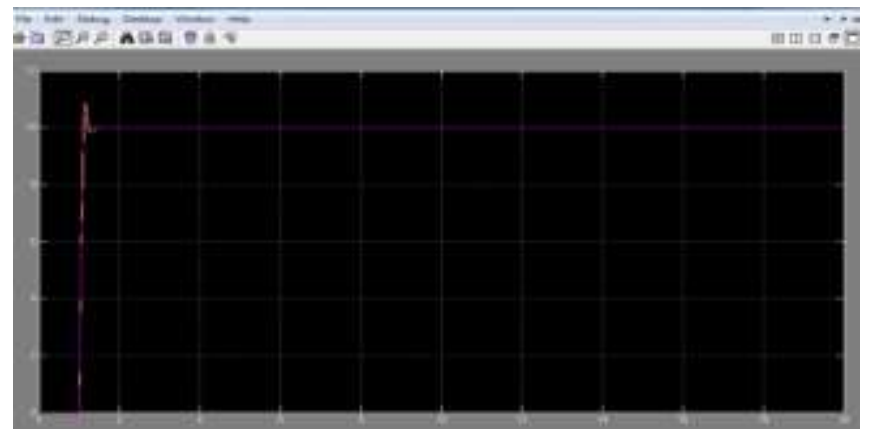

Fig 27 Dynamic tracking with fuzzy controller

\subsection{D Motion Simulations of Gear and Worm}

After the coordinate transformation of the worm and gear, placing them in the same space, let the gear rotate around 
the Zaxis, and the worm rotate around the $\mathrm{X}$ axis. And then we add additionally the characteristics of vision persistence to demonstrate the 3D motion simulation of worm grinding.

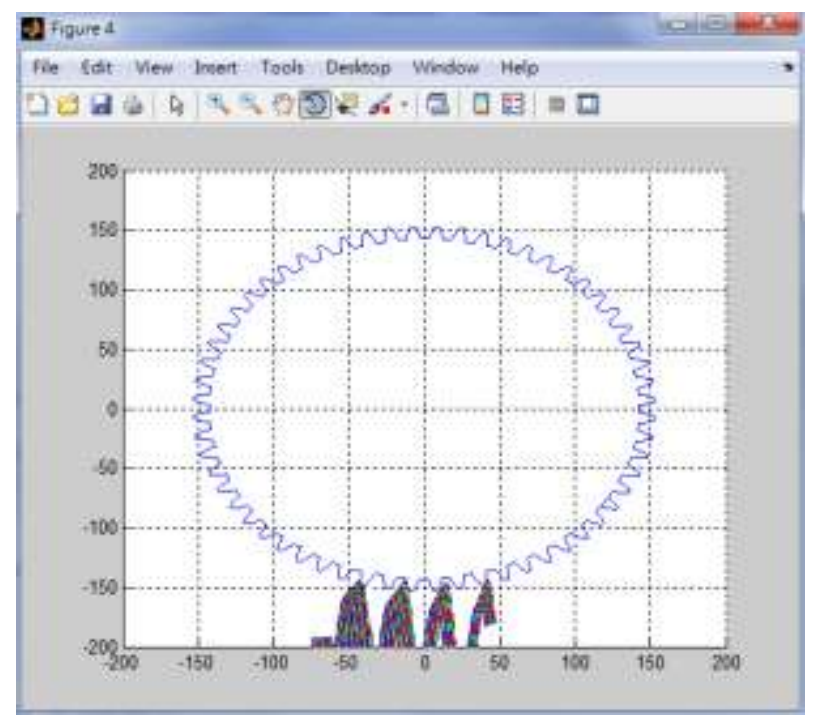

Fig 28. Plane of worm and gear

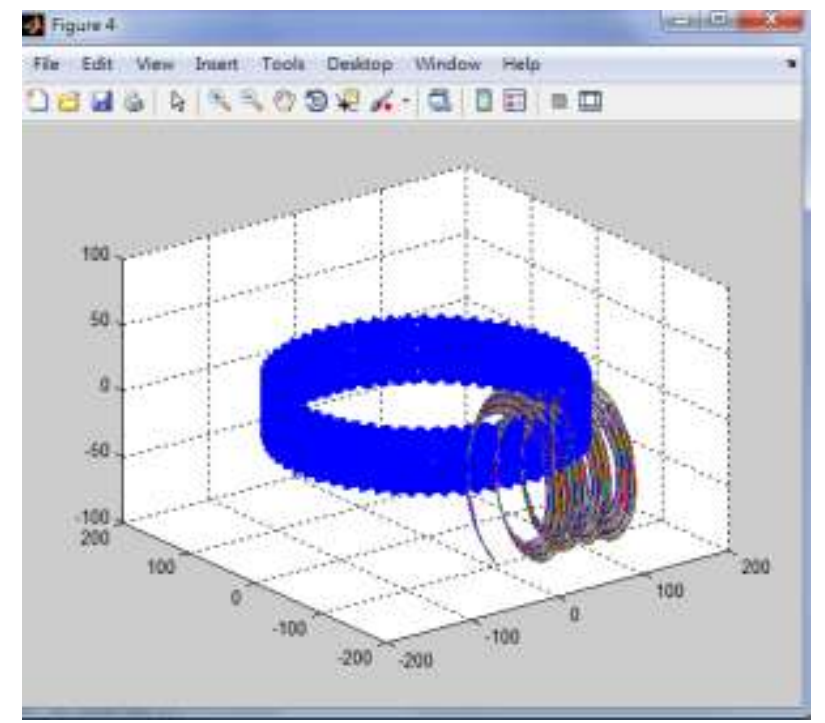

Fig 29. 3-D of gear and worm

\section{CONCLUSIONS AND FUTURE PROSPECTS}

\subsection{Conclusions}

In the beginning of this article, we derive the mathematical formula of worm and gear. Using MATLAB software, we construct a plane and3D model of worm and gear to demonstrate 3D dynamic simulation of worm grinding.

The basic principle operation of electronic gear box is to control each feed axis, feed rate, the rotation axis of the rotation angle and the constructed gear-shape engagement. From the simulation result, it shows that the constructed speed of leading axis (worm wheel + wheel tangential feed + wheel axial feed) is equal to the following axis(gear wheel) speed. Wherein, we use self-tuning fuzzy inference to achieve the same output behavior by using synchronous tracking technique.

\section{REFERENCES}

[1] F. L. Litvin, and A. Fuentes, "Gear Geometry and Applied Theory," $2^{\text {nd }}$ Edition, Cambrige University Press(1994)

[2] H. Koga, K. Umezawa, and H.C. Miao, "Analysis of Plunge Shaving Process for Helical Gears with Tooth Modification,"ASME, Power Transmission and Gearing Conference, DE-Vol. 88, pp.275-281 (1996)

[3] H. S. Fang and C. B. Tsay, "Mathematical model and bearing milling contacts of the ZK-type worm gear set cut by oversize hob cutters,"Journal of Mechanism and Machine Theory, Vol. 31, n. 3, pp. 271-282 (2000)

[4] F.L. Litvin, A. Fuentes, I. Gonzalez-Perez, L. Carvenali, K. Kawasaki, and R.F. Handschuh, "Modified Involute Helical Gears: Computerized Design, Simulation of Meshing and Stress Analysis,"Computer Methods in Applied Mechanics and Engineering, Vol.192,Issues 33-34, pp. 3619-3655 (2003)

[5] K. Mao, "Gear Tooth Contact Analysis and Its Application in the reduction of Fatigue Wear,"Wear, Vol.262, Issues 11-12, pp. 1281-1288 (2007) 